
APAE No. 106
AEC Research and
Development Report
UC-81, Reactors, Power
(Special Distribution)

\title{
CRITERIA FOR EVALUATING HAZARDS \\ INVOLVED IN PROPOSED TESTS ON AND/OR MODIFICATIONS TO THE SM-1
}

\author{
By : \\ J. F. Scoles
}

Approved by:

M. H. Dixon, Project Engineer

Issued: October 18,1961

Contract No. AT-(30-1)-2639, with U.S. Atomic Energy Commission, New York Operations Offiçe

ALCO PRODUCTS, INC.

Nuclear Power Engineering Dept.

P. O. Box 414

Schenectady 1, N. Y. 


\section{ABSTRACT}

This report elucidates principles of hazards evaluation. The concept of hazards potential is introduced and utilized to show how a reactor system perturbation will influence its nuclear safety. Literature relating to reactor safety is referenced to provide the sources of information required for hazards analyses and show how they influence a hazards evaluation. A checklist of items which should be considered in evaluating a change, test, or modification is presented. 


\section{TABLE OF CONTENTS}

$\underline{\text { Page }}$

ABSTRACT

SUMMARY

1.0 INTRODUCTION

1.1 Purpose of the Criteria

1.2 Philosophy and Scope

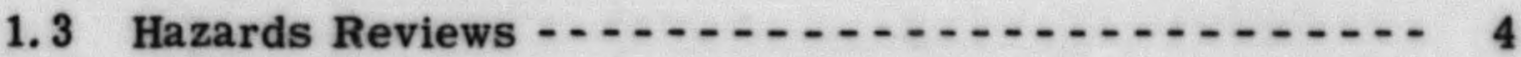

2. 0 PRINCIPLES OF HAZARDS EVALUATION

2. 1 Approach

2. 2 Production of Radioisotopes - 8

2. 3 Containment of Radioisotopes - 9

2.4 Distribution of Contained and Uncontained Radioisotopes - 10

3. 0 GUIDELINES FOR HAZARDS EVALUATION OF PRESSURIZED

WATER REACTORS $-\ldots \ldots \ldots \ldots$

3. 1 Ir.tegrity of Fuel, Primary System and Vapor Container - 12

3. 2 Nuclear Characteristics $\ldots \ldots \ldots$

3.3 Hydraulie and Thermal Characteristics _... 14

3.4 Instrumentation $\ldots \ldots \ldots \ldots$

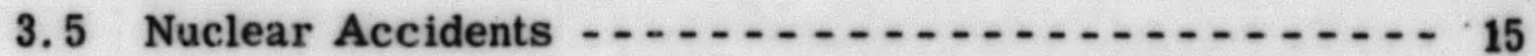

4. 0 LIMITING TECHNICAL SPECIFICATIONS FOR THE SM-1 $\ldots 17$ APPENDIX A - SUMMARY CHECK LIST OF ITEMS TO BE CONSIDERED IN HAZARDS REVIEWS $\ldots \ldots \ldots$

BIBLIOGRAPHY

\section{LIST OF TABLES}

Table

Title

$\underline{\text { Page }}$

Table of Parameters 


\section{SUMMARY}

The purpose of this report is to provide the Hazards Evaluation Group (HEG) with guidelines to permit them to establish and maintain an acceptable risk level with regard to changes in facility design, core design, limits of operation, and operating procedures and the conduct of proposed tests. The report makes the assumption that an acceptable hazards summary report has been written and that the facility is approved for operation; therefore, attention in this report is upon the hazards potential of perturbations to an acceptable system. The nature and extent of technical and administrative audits which should be given to hazards analyses is discussed.

The underlying concepts of hazards potential are introduced, and utilized to show how the best engineering determination of the probability, possible extent, and consequences of loss of control of radioactivity or nuclear radiations are factored into hazards evaluation. The importance of fission and activation product inventory and its effects upon the possible hazards is presented. The problems anticipated in the event that fission or activation products escape from the fuel, primary system, and vapor containment, respectively, are discussed.

In Section 3, guidelines are provided for hazards evaluation of pressurized water reactors. The integrity of the fuel, primary system and vapor container, fission product release fractions, inherent safety mechanisms, nuclear excursions, power distributions, and transient nuclear phenomena are discussed. Pressures and temperatures in the primary system, vapor container pressure buildup after an accident, and burnout safety factors are also discussed. Emphasis in instrumentation is on reliability, failure-to-safety, continuity of nuclear instrumentation, and methods required to achieve these. The manner in which perturbations to the system influence the maximum credible accidents and other accidents is discussed.

A table of technical specifications for SM-1 with comments on the source and significance of the parameters is provided in Section 4. The Appendix contains a list of questions which should be answered by a hazards report. 


\subsection{INTRODUCTION}

A set of criteria for evaluating hazards of proposed tests or modifications on nuclear power plants has been needed to assure that a proper technical audit of hazards reports is achieved and a high level of safety is maintained in the Army Reactors Program. This report is designed to fulfill this need.

Nominal risks accepted in conventional industries and other human functions have been extensively studied. It is not possible at this time, with the nuclear accident data now available, to place reactor safety on the same sort of numerical risk basis. However, an effort will be made in the following pages to show how hazards analyses of reactor system perturbations can be placed upon a pseudoquantitative basis.

A previous draft of the report was issued as AP Note 301. The present report has been rewritten to reflect more basic philosophy of hazards evaluations, to provide additional explanations of some of the values used for limiting parameters for the SM-1, and to take into account comments received on the earlier draft. It is the intent that this report supersede AP Note 301. The contents of this report were developed under Item 1.4 of the AEC-Army PWR Support Program in accordance with AP Note 286, Addendum 1, Revision 1.

\subsection{PURPOSE OF THE CRITERIA}

Research and development tests and changes in facility design, reactor design and operating procedures must be reviewed to maintain an acceptably low risk level for every reactor. $(1,2,3,4)$ The objective of this report is to provide guidelines which will establish a basis for hazards analyses of proposed tests on and/or modifications to Army pressurized water reactors. The same guidelines will offer a basis for technical review of hazards analyses which are performed. The criteria cannot explicitly cover every case which might develop. However, the criteria set forth in this document should lead the attention of the qualified reviewer during this technical audit to the hazard-sensitive items which are affected by the test or modification. The limiting parameters presented for the SM-1 reactor offer a reasonable basis for judging the hazards potential of the perturbations imposed upon the system by a given test or modification.

\subsection{PHILOSOPHY AND SCOPE}

This report treats hazards analyses of proposed tests on and/or modifications to Army pressurized water reactors. In particular, application to the SM-1 is made more facile by the provision of a table of limiting system parameters. Addenda to this report are planned to give the limiting technical specifications for the SM-1A and PM-2A. The general principles and guidelines developed in this document are applicable to the SM-1A and PM-2A with littie modification.

This report is limited to analysis of proposed perturbations to an otherwise acceptable system. Therefore, it must be assumed that a hazards summary 
report has been prepared for the particular plant being investigated and that it has been approved for operation. The increase in hazards potential beyond that due to the approved operations of the plant investigated should be analyzed in hazard studies of proposed tests or modifications to nuclear plants.

This report presents guidelines and limitations for selected system parameters. The limits given are boun laries to known safe regions of operation based upon the existing technology and understanding of the particular plant. Operations outside the limits specified or implied in this report cannot be approved by the criteria; but rather must be proven safe by testing, advancement in technology or relaxation of previous or more basic criteria.

\subsection{HAZARDS REVIEWS}

The need for independent technical audit of hazards analyses is often stressed in the literature. The administrative approval channels provide the authority and framework for accomplishing the technical reviews. Annex A to the charter of the ANPP Hazards Evaluation Group (5) gives administrative procedures for evaluation and review of the hazards involved in proposed tests, modifications, and operating procedures for all nuclear plants under cognizance of the Army Nuclear Power Program (ANPP). Annex A identified the review procedures as a function of degree of safety change, funding, ownership, and operating authority for ANPP reactors. Hazards approval of tests on and/or modifications to the SM-1 will be accomplished by the methods provided by Appendix L to "SM-1 Operation Plan." (6)

Briefly, Appendix L specifies that Alco Products, Inc., as a contractor for the AEC, is required to prepare and submit to the New York Operations Office (NYOO) a report of the hazards involved in the test or modification which Alco proposes. Modification to the plant or operating procedure sponsored by the Corps of Engineers will be supported as required by hazards reports prepared either by Nuclear Power Field Office (NPFO) or Alco Products, Inc., under contract with NPFO. These hazards analyses are subinitted by NYOO or ANPP and are reviewed by the Hazards Evaluation Group (HEG) on the basis of the criteria set forth in this document. Upon favorable recommendation by HEG that the proposed test or modification does not involve hazards greater than those defined in this report, ANPP will advise NPFO of the acceptability of the test or modification. ANPP will also advise the Licensing and Regulation Divisions (L\&R) of the intention to perform the test, modify the plant, or change the operating procedures. If the contracting office (NYOO or NPFO) considers that the proposed test or modification involves hazards beyond their competence to evaluate or greater than those defined in the criteria or if the HEG concludes that the test or modification involves hazards greater than those defined in the criteria, the hazards report will be submitted through the AEC's Assistant General Manager for Regulation and Safety (AGMRS) to obtain AEC comments aná recommendations. 
As a matter of policy, AEC comments and recommendations on nuclear safety are considered binding within the ANPP. More detail and a flow chart are given in reference (6).

The acceptability of a nuclear hazard is a matter of judgment. Any test or modification which results in no increase in probability or extent of any credible nuclear accident may be considered acceptable from a nuclear safety standpoint. The unperturbed system safety should be that described in the most recent hazards summary report plus any more recent topical hazards reports which are applicable (i.e. any approved hazards analysis of modifications, tests, or safety questions constitutes a portion of the hazards analysis for the reactor). The operating manual, standard operating procedures, and test procedures for hazard-approved tests define the normal operating limits of the SM-1. The nuclear hazards possible within these operating limits have been accepted by their approval. The limiting parameters presented in these criteria are such that no significant increase in hazards potential will result. Any test or modification resulting in a significant increase in hazards potential over that of the existing system will be referred to the AEC by the above procedure. 


\subsection{PRINCIPLES OF HAZARDS EVALUATION}

\subsection{APPROACH}

A hazards report should present the best engineering determination of the probability, possible extent, and consequences of loss of control of radioactivity or nuclear radiations. In the case of a hazards analysis of a proposed test, modification, or change in operating procedures, the change in hazards potential of the system must be investigated. The hazards potential, $\mathrm{H}$, of a given reactor may be thought of as,

$$
H=\sum_{i=i_{0}}^{i_{m}} P_{i} A_{i}
$$

where,

$\mathbf{P}_{\mathbf{i}}=$ the probability of the potential accident $\mathbf{i}$,

$A_{i}=$ a measure of severity of consequences of accident $i$,

$i_{0}=$ the accident of minimum measurable consequences,

$i_{m}=$ the maximum credible accident.

It is extremely difficult to evaluate $\mathrm{H}$ for any given reactor system. It is practically impossible to assess the probability of each potential accident and assignment of numerical values to the severity of consequences of an accident also poses great problems. The measure of the severity of an accident must consider both economic and humanitarian aspects. (Siddal suggests(1)(2) a means of evaluating reactor safety and points out some of the drawbacks.) This formulation, though not now a realistic approach to overall hazards, may be very helpful in considering the change in hazards potential due to testing, changes in procedures, and system modifications.

A given system perturbation may influence the probability and extent of several potential accidents. It then becomes the burden of the hazards analysis to provide and substantiate the best engineering judgment of the net overall change in hazards potential. Perturbations which contribute no significant net increase in hazards potential will be considered acceptable. Any system perturbation which causes significant net increase in hazards potential should receive an extensive review to ascertain whether the added risk which it poses is acceptable. Due to the present uncertainty of evaluation of the probability or the severity of a nuclear accident, the concept of hazards potential is somewhat nebulous. The best evaluation of hazards potential which can be hoped for is merely an intuitive engineering judgment of whether the safety change is large or small. The hazards report must provide sufficient information to permit independent judgments to be made of the reactor safety. 
The various factors considered in nuclear safety analysis are usually of importance only insofar as they effect the ultimate control of nuclear radiations. The factors contributing to loss of control of radiations and the ensuing hazards which might possibly result from an accident are discussed in the foilowing paragraphs.

To minimize the hazards potential, it is necessary to keep the radioisotope inventory to a minimum, keep it contained, and restrict its distribution if it should become uncontained. The fission products are a function of reactor history; however, the system should be designed to keep activation products to a minimum.

\subsection{PRODUCTION OF RADIOISOTOPES}

The extent of possible release of radioisotopes in the event of a reactor accident depends upon the amount present at the time of the accident. Fission products and activation products are the only radioisotopes present due to reactor operation. The amount of fission products present is, for any practical hazard analysis, a function of the fuel history (i. e. the fission rate or power generation rate and the operating and shutdown times). The activation products present are principally a function of reactor and primary system design. For most hypothetical accident problems, the fission products so heavily dominate the activity release that the activation products may be neglected.

The early work by Way and Wigner $(7,8)$ remains the handiest and most useful approximation to the total fission product activity. The equations below follow directly from their work for a single reactor operation of duration $\mathrm{T}$.

$$
\begin{aligned}
& A(\beta)=15.4 \text { F } t^{-0.2}-(t+T)-0.2 \text { curies } \\
& A(\gamma)=7.9 \text { F } t^{-0.2}-(t+T)^{-0.2} \text { equivalent curies }
\end{aligned}
$$

where,

$$
\begin{aligned}
& \mathrm{F}=\text { fission rate (watts) } \\
& \mathrm{T}=\text { reactor operating time }(\mathrm{sec}) \\
& \mathrm{t}=\text { time since reactor shutdown }(\mathrm{sec})
\end{aligned}
$$

The contributions from separate reactor operations are additive. These equations give results which experience has shown are within about 20 percent of the correct total activities. Several other studies haye given the gross fission product decay energy as a function of operating history $(9,10,11,12,13)$. Blomeke and Todd(14) have produced a comprehensive set of calculations which provide a means of grouping the fission product inventory by chemical properties to facilitate release calculations. Most calculations of fission product inventory for hazards analysis are based upon an essentially equilibrium fission product level. The inventory for the analyses then becomes approximately a function of average power generated for an old (in usage time) fuel assembly. Wherever possible,experimentation which increases the probability of fission product release should be performed with fresh fuel assemblies. This reduces the hazards potential by reducing the severity of the consequences. 
Activation products are produced anywhere in the system where neutrons are prevalent. The principal activation products of importance to hazards analysis are those in the primary coolant and those in the fuel assemblies themselves. Radiation hazards can result from activated plant comyonents but they are not as likely to become uncontrolled as those in the coolant or core assembly. The amount of activation products produced is a function of primary system design and reactor operation history. In an existing plant, the potential activation product buildup may be altered by modifying the reactor operation program or by changing or adding materials in the primary system. The problems developed in pressurized water systems are discussed in Section 3. 0.

The production, distribution, and removal of activation products is a complex function of system design, operating program, plant chemistry, and primary coolant purification procedures. Variation of any of the factors contributing to activation product inventory should be discussed in detail and the consequences appraised in a hazards analysis.

\subsection{CONTAINMENT OF RADIOISOTOPES}

The cuntainment of radioisotopes in the fuel, primary system, and vapor container during normal operation, transient operation and credible accidents must be evaluated for a complete hazards analysis. Any test or modification which alters the integrity of any of the containment barriers reguires a containment re-analysis.

The first barrier against fission product release is the fuel assemblv The power density, provisions for cooling, and the fuel composition and design determine the possible mechanisms and amount of fission product release from the fuel assemblies. Recoil fission fragments may escape the fuel through thin cladding or greater releases may occur through failures in the fuel. In the case of an accident, meltdown of the fuel may occur. Economics of the plant and state of development may dictate that low level leakage of fission products from fuel assemblies may be easier to cope with than to eliminate. The design, fabrication, and operation conditions should be such that these will provide reasonable assurance that no untenable large release of fission products from the fuel will occur. Particular attention should be given to testing of untried fuel assemblies to assure that the hazards of any possible radionuclide release are adequately evaluated. The review requirements are dependent upon the potential hazards accrued.

The primary system of closed cycle reactors affords a containment barrier against release of fission and activation products which may be found in the primary coolant. Major failures of the primary coolant system may be responsible for consequences approaching or equalling the maximum credible accident. The hazards report should provide an analysis of any change in integrity of the primary system which might result from a proposed test or modification. 
The vapor containment structure provides the last line of defense against release of radioactivity to the atmosphere. In some cases, the consequences of an atmospheric release or so minor that a tight containment is not considered justified (i.e. , the PM-1 reactor building is not leak-tight). Any change or test which threatens to compromise the vapor containment to a greater degree than that assumed in the latest hazards summary report should be closely scrutinized to assure no additional hazard is introduced. Some added compromise of the vapor containment may be permissible, but will be submitted to AEC review.

\section{4 DISTRIBUTION OF UNCONTAINED RADIOISOTOPFS}

Violation of each of the containment barriers, the fuel, the primary coolant system, and the vapor container causes an abnormal distribution of radioactive materials and contributes to a reduced control of radioactive nuclides. The abnormal distribution of radioactivity in the primary coolant system, in the vapor container, or in the atmosphere can result in excessive dosages to the operating personnel or to the nearby inhabitants.

While the fuel is intact, the fission products and core activation products are usually contained adequately within the primary shielding. Modifications or tests which threaten to increase the release of activity from the fuel should be avoided, but may be performed if their danger is recognized and precautions are taken to observe the release if it occurs and to cope with the potential radiation problems. Many reactors can tolerate increased activity levels in the primary coolant without serious increase in hazards potential.

Release of activity from the primary system through leaks or failures causes potential hazard to maintenance operations and places the release one step closer to an environmental release.

Failure of the last containment barrier, resulting in an environmental release of activity, brings the potential hazard to the surrounding area. Usually the distribution of radionuclides is calculated by using adaptations of $O$. G. Sutton's atmospheric diffusion equation $(4,15,16,17)$. A meteorological history of a year or more is needed to establish a weather pattern with any confidence. The basic atmospheric diffusion calculation methods used should be a part of the hazards summary report, and in investigating the effects of perturbations, the same methods should usually be followed.

Basic objectives for population exposures have been expressed by the $\operatorname{AEC}(18)$ as:

1. Serious injury to individuals off-site should be avoided if an unlikely, but still credible accident should occur.

2. Even if a more serious accident (not normally considered credible) should occur, the number of people killed should not be catastrophic. 
3. The exposure of large numbers of people in terms of total population dose should be low.

For the most part, tests and modifications will be considered acceptable as long as their potential hazards meet these general criteria. 


\section{0 GUIDELINES FOR HAZARDS EVALUATION OF PRESSURIZED WATER REACTORS}

The various pressurized water reactors are characterized by potential hazards of similar form. The origin and course of accidents and their consequences are of the same general type. Reactor safety criteria which apply in general to pressurized water reactors are discussed in this section.

\subsection{INTEGRITY OF THE FUEL, PRIMARY SYSTEM, AND VAPOR CONTAINMENT}

Pressurized water reactors will usually have pins, tubes, or flat plates as the smallest basic core fuel module. These modules are assembled into some form of elemental configuration to facilitate handling. The fuel is a sandwich of material bearing fissionable isotopes contained within structural materials which serve to contain the fission products, protect the meat from corrosive action of the coolant, and give structural strength to the assembly. To maintain a low activity level in the primary coolant, it is necessary to assure that the integrity of the basic fuel module is not violated. Cracks, corrosion, rupture, meltdown, or burnout will cause a portion of contained fission products to be released from the fuel. The seriousness of this release depends upon the amount of activity which builds up in the coolant, the consequences of the increased activity level in the coolant, and the prognosis of the problem (i. e. will the difficulty be self-propagating, will the activity level continue to increase).

A cautious approach to test inclusions in operating cores should be followed. If a reactor is designed (and adéquately protected) for core component testing, the possibility of limited fuel module failures may be accepted. However, if contaminated primary coolant or reactivity changes, such as may be possible with the anticipated core inclusion, are compromising to the safety of the facility, then the test component should not be placed in the core. Addition of instrumentation to detect failures, emergency cleanup plans, and revised operating procedures may be required as needed to assure that no undetected hazard results from core component testing. Proof-testing of fuel samples in special test facilities is advisable if their nuclear, thermal, hydraulic, metallurgical, or fabrication characteristics are significantly different from existing fuel types. Nuclear testing may be accomplished in a critical facility experiment and should include reactivity worth and power distribution. Metallurgical testing should include metallographic examinations and other destructive and non-destructive testing programs requirod to insure the integrity of the cladding and the bonding. Thermal and hydraulic characteristics may be analyzed by instrumented flow tests, nuclear power distribution measurements, and correlations developed from previous experiments on similar configurations, or by performing a special experiment for new and untried configurations. 
Fabrication should be with strict quality control and should conform to the requirements of nuclear, thermal, hydraulic, and metallurgical specifications. Proof-testing of completed fuel assemblies in testing reactors is a desirable means of showing that the assembly is acceptable. However, if the new assembly is sufficiently similar to previous assemblies and the testing and analysis indicate it is sufficiently conservative, it may be tested in field plants. One of the primary functions of a technical review of the hazards analysis is to provide independent evaluation of this type test at the point where the decision to accept or reject the nuclear hazard has been reduced to a matter of judgment.

The structural integrity of the primary system of pressurized water reactors must be maintained to prevent contamination of the vicinity of the primary system, to prevent possible loss of coolant to the core, and to minimize possibility of vapor containment failure. Alterations to any part of the primary system should be done in such a manner that there is no compromise of structural strength or leak tightness. Tests, changes in operating procedures, and system modifications which alter the pressure or temperature of the primary system during any mode of operation must be reviewed to assure that no variations are introdluced which are beyond the safe limits of the system.

The neutron irradiation damage to the reactor vessel wall (particularly with carbon steel vessels) must be considered in all perturbations to the system. Usually, a curve of permissible heatup, cooldown and pressurization rates is prepared for the operating procedures for reactors having carbon steel reactor vessels subjected to neutron damage (see Section 4 for the SM-1). No perturbation should be permitted which causes pressures, temperatures, or gradients outside of the permissible range.

The vapor containment for pressurized water reactors must maintain its structural integrity through a release of the primary coolant with its maximum credible stored energy. The leak-tightness under the pressures of the maximum credible accident must be such that the airborne concentration of radioactive material must not be unduly hazardous to nearby inhabitants. All penetrations must meet the same leakage requirements as the vessel. Periodic leak testing is a desirable way of demonstrating vapor containment integrity. Particular caution should be exercised lest undue quantities of material added within the vapor containment reduce the free volume to such an extent that the pressure buildup following the maximum credible accident exceeds permissible limits for the containment vessel.

\subsection{NUCLEAR CHARACTERISTICS}

In general, the excess reactivity of any reactor should be restricted so that accidental step or ramp changes in reactivity within credible limitations cannot cause a serious hazard. All means of reactivity addition or removal created or eliminated by the particular system perturbation should be explored. Loading and all phases of operating procedures should be scrutinized and care- 
fully controlled, particularly for new core configurations. Critical experiments should be performed for all new loadings.

For the most part, power excursions with pressurized water reactors are self-limiting. This is, the characteristic negative temperature coefficient and void formation will halt the preponderance of credible power excursions before serious damage ensues. However, any change which alters the credible rate of additions or the amount of excess reactivity should be thoroughly analyzed to determine the potential peak power and energy output in the event of an excursion. Associated effects of an excursion which should be investigated are:

1. Possibility of mechanical damage to the core, primary system, or control mechanisms.

2. Possibility of excessive heating of fuel or other core components (fuel meltdown, burnout, or distortion, etc. ).

3. Possibility of excessive radiation exposures due to power pulse, loss of shielding resulting from the excursion, or distribution of active nuclides.

Changes in power distributions resulting from core inclusions, deletions, or alterations should always be a point of concern. Of particular concern is placement of test specimens differing significantly from the fuel normally used. Flux mapping in a critical experiment is a valuable tool in analyzing the perturbed power distributions.

Wherever possible, inherently safe designs should be utilized. Instrumentation or operative safety procedures are poor substitutes for good design.

\subsection{HYDRAULIC AND THERMAL CHARACT ERISTICS}

Of primary importance to inherently safe reactor design is heat removal from the fuel assemblies. Most high power density pressurized water reactors will experience fuel meltdown upon complete loss of coolant. Integrity of the primary system design must be relied upon to provide adequate coolant for the fuel assemblies under all conditions of operation. The minimum burnout heat flux ratio is a measure of the safety factor in the thermal design. The actual ratio must always be greater than 1.0 , but the amount by which it is required ta exceed 1.0 varies. If confidence in the burnout correlations is sufficiently great, than a ratio as low as 1.1 may be permitted.

The correlations in use at present by ALCOfor plate-type fuel elements have an uncertainty factor of $1.2^{(19)}$. Older correlations had an uncertainty of 1.:5. In no case can the calculated burnout ratios be any more accurate than the applicability or accuracy of the correlation by which they are determined. Experience has shown 
that the lowest burnout ratios occur during transient modes of reactor operation. In practice, an arbitrary higher burnout ratio is selected for design purposes. using steady state conditions, and the minimum burnout ratio for the worst transient conditions is determined. This minimum ratio should be above 1.0 by at least the amount of the uncertainty in the correlations. Since the minimum acceptable burnout ratios cannot be specified, the hazards report should provide sufficient information that an acceptable minimum burnout ratio for the methods and conditions used may be evaluated. With the present ALCO methods, using plate-type elements in the SM-1, PM-2A, or SM 1A, the minimura burnout ratios should not be permitted to drop below 1.2 in the most severe possible transient modes of operation.

If a severe extension of the burnout correlations is used, a larger minimum burnout ratio is advisable. The minimum acceptable burnout ratio in this case resolves to a matter of judgment and should be carefully reviewed and considered.

Normal operating and transient pressures, temperatures and flows should be within the limits of the system. Digital computer models have proven themselves sufficiently accurate for most applications $(20,21)$. The need for special instrumentation and administration of limits is a matter of judgment depending upon the particular case.

The kinetics of any credible accident should not be made more severe beyond the system limitations by any perturbation. Any factor which contributes to increase of energy release in the maximum credible accident or decrease in the ability of the vapor containment to contain the release should be reviewed.

\section{4 INSTRUMENTATION AND CONTROL}

The instrumentation of a reactor plant provides a means of interpretation of the observable phenomena of the system. The instrumentation and control systems are service functions of a plant and should be altered only when increased service is needed or when improved service may be supplied. When changes are made, no compromise of the existing services should be permitted. Reliability is the watchword with regard to instrumentation and controls changes. This is accomplished by judiciously chosen redundant and coincidence circuits, design for failure-to-safety, and use of proven components.

Continuity of nuclear instrumentation is required from source neutrons to full power. This is accomplished by overlapping ranges of instrumentation. No shortcut of this function can be permitted.

\section{5 NUCLEAR ACCIDENTS}

Changes in hazards potential through perturbations to the system are discussed throughout this report. If the hazards potential is not significantly in- 
creased, then the change should be considered acceptable on the basis of nuclear safety. If a net increase in hazards potential results from the change, the hazards analysis should provide sufficient basis for and offer judgmient of the acceptability of the test. The changes should be subjected to AEC review. It is the purpose of the reviews to determine whether the judgments of hazards acceptability are valid. 


\subsection{LIMITING TECHNICAL SPECIFICATIONS FOR THE SM-1}

The following table of limiting parameters for the SM-1 are those judged to be significant from the standpoint of safe operation. Where design values only are given, neither experience nor judgment has necessitated the setting of a maximum or minimum limiting value. Operation outside of the limits specified should not be done without proof of safety and the concurrence of the AEC.

Additional information on normal SM-1 operating parameters may be obtained from the design report, (22) the latest hazards summary report, and from a design data summary report. (20)

The numbers given are based on the present SM-1 plant and state of technology. The notes following the table should be observed in all applications.

The primary system heatup or cooldown rate should be restricted to $30^{\circ} \mathrm{F}$ per hour to protect the wye valve. Primary vessel embrittlement further dictates that the pressure be limited to $600 \mathrm{psig}$ when the system temperature is below $305^{\circ} \mathrm{F}$. 
TABLE I

TABLE OF PARAMETERS

(See notes following table for explanations)

Parameters

Operating Limits

1. Reactor thermal power ( $M$ w )

2. Burnout safety factor

3. Maximum contained energy (Btu) Reactivity

4. Overall core temp. coeff. $\left({ }^{0} \mathbf{F}^{-1}\right)$

5. Reactor period (sec)

6. Shutdown control margin $(\mathrm{H})(\% \rho)$

7. Excess core reactivity at $68^{\circ} \mathbf{F}(\% \rho)$

8. Control rod withdrawal rate (in $/ \mathrm{min}$ )

9. Negative reactivity worth of liquid

poison system $(\% \rho)$

Radioactivity

10. Fission product activity at stack

11. Activity level for release of liquid wastes

12. Disposal of contaminated solid waste

13. Occupational exposure ( P) (Rems/Wk)

(Rems/Qfr)

(Rems/Yr)

Pressure

14. Primary system pressure (Q) (psia)

15. Setting of first pressure relief valve (pressurizer) (psia)

16. Pressurizer pressure under operating conditions (psia)

17. Steam generator pressure (psia) Tube side

18. Secondary steam pressure (psia)

19. Steam temperature $(\mathrm{T})\left({ }^{\circ} \mathrm{F}\right)$

20. Primary coolant flow (gpm)

22. Reactor exist coolant bulk temperature $\left({ }^{\circ} \mathrm{F}\right)$
Min.

$\underline{\text { Value }}$

Value

1.2 (C)

$10(A)$

$4.8 \times 10^{6}(\mathrm{D})$

$-2.6 \times 10^{-4}$

at $440^{\circ} \mathrm{F}(\mathrm{F})$

3 (G)

$3(\mathrm{I}) \quad 5.4(\mathrm{~J})$

17 (K)

3 (M)

22

(N)
Max.

$\underline{\text { Value }}$

13.4 (B)

$7.3 \times 10^{6}(\mathrm{E})$

L

(O)

(O)

0.3

5.0

1600

1500

$1175(\mathrm{R}) \quad 1200$

1600

500

213 full load

422 no load

429 full load

440 no load

3860

448 full load

440 no load
$1310(\mathrm{~S})$

500 (S)

480 (U)

$480(W)$ 
Notes to Table 1

A. $10 \mathrm{Mw}$ was the design requirement of Contract AT(11-1)1318. However, a measured ivalue of 10.8 was obtained for the steady state full power output during the startup testing. (Ref. 25)

B. Limited by reactor scram setting (Ref. 23). No analysis has been made relative to the hazards of operating at high power levels.

C. Based upon current ALCO methods for plate-type fuel elements.

D. The contained energy of the primary and secondary system at full load.

E. The contained energy of the primary and secondary system at maximum during the assumed maximum credible accident (Ref. 22).

F. The negative temperature coefficient has been measured several times during core life. The measurements indicate no change in the coefficient with burnup. At $440^{\circ} \mathrm{F}$, the temperature coefficient is $-3.5 \mathrm{C} / \mathrm{F}$. Using a $\beta$ effective of 0.0073 , this corresponds to $-2.56 / 10^{-4} \Delta \mathrm{K} /{ }^{\circ} \mathrm{F}$.

G. Very short periods can cause serious damage to the SM-1 because of the large power excursion before scram due to power level or void formation. Instrumentation can reliably evaluate and control to periods as low as $\mathbf{3}$ sec, and no need should develop requiring a period less than $3 \mathrm{sec}$ to be allowed.

H. Based upon control by control rods alone. See item (9) for boron injection worth.

I. Arbitrary value based upon present system. Any credible combination of incapacitated control mechanisms should not prevent a hot shutdown, and more desirably should not prevent a cold, clean shutdown.

J. Based upon the original design criteria the design value for the shutdown margin is based upon a seven rod bank worth of $20.8 \% \rho$. The latter value is the best estimate of the worth of seven europium type absorbers with europium flux suppressors fabricated at the ends of the control rod fuel element plates.

K. Experience value from SM-1 Core I based on rod calibrations made during core life.

L. The maximum excess reactivity to be allowed is determined by the total control rod worth available minus the minimum shutdown margin of $3 \% \rho$. For example, for a seven rod bank worth of $20.8 \% \rho$, the maximum allowed excess reactivity would be $17.8 \% \rho$. 
M. The rod withdrawal rate represents a compromise between values which would speed up reactor operations and a value which would reduce hazards associated with possible rod withdrawal accidents.

N. $47 \mathrm{gm}$ of $\mathrm{B}^{10}$ in the water volume of the active core will provide a $5 \%$ shutdown margin for the core in its most reactive ccndition with rods full out. This corresponds to $1.55 \mathrm{~kg}$ of $\mathrm{B}^{10}$ in the entire primary system. By the existing method of inserting boric acid, this required amount of $\mathrm{B}^{10}$ can be added in about $2 \mathrm{hr}$. The maximum amount of $\mathrm{B}^{10}$ that can be added to the primary system by existing methods is about $8.15 \mathrm{~kg}$. This could be accomplished in abrut $22 \mathrm{hr}$.

O. Limits are as specified in 10 CFR, Part 20.

P. As an operational guide, daily dose in excess of $50 \mathrm{Mr}$ will not normally be permitted except in cases of operationarmecessity. (Ref. 26).

Q. Pressures and temperatures must be maintained within the safe range as indicated in the standard operating procedures. In no case should the primary system pressure be allowed to exceed 600 psig if its temperature is below $305^{\circ} \mathrm{F}$.

R. Pressurizer heaters automatically actuate.

S. Pressure relief valve opens.

T. At steam generator.

U. High temperature scram on steam generator.

V. Low flow scram setting.

W. High temperature scram, primary system. 


\section{APPENDIX A \\ A SUMMARY CHECK LIST OF ITEMS TO BE CONSIDERED IN HAZARDS}

A number of items need to be considered in 'analyzing a change, test, or modification at a reactor facility. The following outline gives potentially hazardsensitive areas and specific questions which should be answered in a hazards analysis. The answers which these questions must have, to be consistent with safe reactor operation, are detailed in Sections 3 and 4 of this report. This list of questions is by no means the only consideration which should be included in a hazards analysis. It is anticipated, however, that the particular case and these guiding questions will lead hazards analysts and reviewers to a substantially complete coverage of the safety questions involved.

The proposed amended Paragraph 50.36, "Designation of Technical Specifications, " Appendix A, of reference (28), has been particularly helpful in preparation of this list.

\section{A. Reactor Site}

1. Location.

Does the proposed change involve a change in reactor location?

Does the proposed change alter the nature of the surrounding environment or its hazards sensitivity?

2. Exclusion Area

Is there a change in the minimum exclusion radius ?

Is there a significant change in the principal activities carried on within the exclusion area?

B. Containment

Does the system modification alter the vapor containment yield strength or failure characteristics?

Is a mutation of the vapor containment leakage rate brought about by the proposed modification?

Does the proposal consist of such a vicissitude that a significant decrease of vapor container free volume results ? 


\section{Primary Coolant System}

Has the coolant flow rate,configuration, or distribution been altered?

Is a change in the coolant operating pressure or pressure gradient anticipated?

Is the system temperature or temperature gradient significantly changed?

Is the structural integrity of any of the primary system components altered or threatened?

Is the maximum anticipated primary coolant activity increased?

Is the change in type, rating, or specifications of any of the primary system components called for?

Have the safety level settings or safety system capacities been altered?

Have the primary coolant purification system or sampling procedures been modified?

\section{Secondary Coolant System}

Is the effect of secondary coolant system perturbations upon primary system variables adequately analyzed?

Is a means of communication between primary and secondary water introduced?

\section{E. Reactor Core}

Has the moderator or reflector material configuration or effectiveness been altered?

Have the fuel element materials, loading, enrichment, or metallurgical composition been' modified?

Have any of the core dimensions, tolerances, or specifications been changed?

Is there a significant change in the temperature or pressure coefficients of reactivity?

Is the total temperature and pressure reactivity defect altered? 
Does the proposed change introduce a question of criticality or available reactivity?

Is the form, amount, net worth, burnup rate, or method of inclusion of the burnable poison changed?

Is the number, net worth, or individual worth of the control elements modified?

Is the minimum shutdown margin reduced? In terms of reactivity? In terms of number of control elements stuck in operating positions? In terms of number of control elements stuck in the most reactive positions ?

Is the type, minimum worth, conditions for use, or design features of auxiliary poison systems aitered?

Is the isotopic or elemental composition of the oore modified?

Is the maximum thermal power, maximum power density, or average power density changed?

Are the fuel surface or central temperatures increased?

Is the minimum burnout safety factor reduced?

F. Control and Safety Systems

Are any safety or control systems eliminated or compromised for this change?

Are any new safety systems needed to replace inherent or other safety systems sacrificed for this change?

Is there any change in the design or function of any of the control actuating mechanisms?

Are the initiating conditions or activation points for scram or other automatic safety devices altered?

Is the time required to consummate a scram changed?

G. Radiation Limits

Is the anticipated liquid or gaseous release activity increased? 
Is there a change or need for change of the radiation level monitors ?

Are means provided for observing failures of fuel elements if they have an increased probability of occurring?

Does the change offer the possibility of exceeding existing waste disposal capacities ?

H. Administrative Controls

Is administrative control utilized as a substitute for needed automatic control?

Is an adequate internal technical hazards audit provided for?

Is additional periodic testing required as a result of the change? 


\section{BIBLIOGRAPHY}

1. Siddall, E., "Reactor Safety Standards and Their Attainment", CRNE-726, September 1957.

2. Siddall, E. , "Statistical Analys is of Reactor Safety Standards," Nucleonics, 17(2), p. 64-69, February 1959.

3. Binford, F. T., "Evaluation of Feactor Hazards," Nuclear Safety, 2(1), p. 10-13, September 1960.

4. Gomberg, H. J., Bassett, et al, "Report on the Possible Effects on the Surrounding Population of an Assumed Release of Fission Products into the Atmosphere," APDA-120, May 1957.

5. Letter from Colonel Gordon B, Page, Chief, Army Nuclear Power Program, to All Personnel, ANPP, February 24, 1961, "Charter of the ANPP Hazards Evaluation Group."

6. SM-1 Operation Plan, Appendix L, Hazards Reports and Inspections, Rev. 2, November 15, 1960.

7. Way, K, and Wigner, E. P., Physical Review 70,115 (1947)

8. Way, K. and Wigner, E. P., Physical Review 73, 1318 (1948)

9. Scoles, J. F., "CalculatedGamma Ray Spectra from U235 Fission Products, FZK-9-132, August 1958.

10. Perkins, J. F. and King, R. W., "Energy Release from Fission Products," ER-2871.

11. Clark, F. H., "Decay of Fission Product Gammas," NDA-27-39, December 1954.

12. Moteff, J.,"Fission Product Decay Gamma Energy Spectrum," APEX-134.

13. Perkins, J. F. and King, R. W., "Energy Release from the Decay of Fission Products," Nuclear Science and Engineering, 3, 726-746 (1958).

14. Blomeks, J. O and Todd, Mary F., "Uranium - 235 Fission Product Production," ORNL-2127, March 1959.

15. Metebrology and Atomic Energy, AECU-3066, July 1955. 


\section{BIBLIOGRAPHY (CONT'D)}

16. Fitzgerald, J. J., Hurwitz, H. Jr., and Tonks, L., "Method for Evaluating Hazards from a Nuclear Accident," KAPL-1045, March 1954.

17. Vance, и. S. , et al, "Theoretical Possibilities and Consequences of Major Accidents in Large Nuclear Power Plants," WASH-740, March 1957.

18. Atomic Energy Commission, Reactcr Site Criteria, (Notice of Proposed Guides) 10 CFR Part 100, February 1961.

19. De Bortoli, R. A., Green, S. J., Le Tourneau, B. W., Troy, M., and Weiss, A., "Forced Convection Heat Transfer Burnout Studies for Water in Rectangular Channels and Round Tubes at Pressure Above 500 Psia," WAPD-188, January 1958.

20. Pyle, R. S., "STDY-2 "A Program for the Thermal Analysis of a Pressurized Water Nuclear Reactor During Steady State Operation," WAPDTM-213, June 1960.

21. Meyer, J. E., Smith, R. B., Gelbard, H. G., George, D. G., and Peterson, W. D., "ART-02-A Program for the Treatment of Reactor Thermal Transients on the IBM-704," WAPD-TM-156, November 1959.

22. Alco Products, Inc., "Phase III Design Analysis for the Army Package Power Reactor," APAE-10, August 1957.

23. Rosen, S.S., "Hazards Summary Report for the Army Package Power Reactor, SM-1 Task XVIII," APAE-2, Revision 1, May 1960.

24. Nuclear Technology Data for SM-1, SM-1A, PM-2A, SM-2," AP Note 357, June 1961.

25. Meem, J. L. , "Initial Operation and Testing of APPR-1," APAE-18, October 1957.

26. Memo, Page to Burlin, Subject: 'Maximum Permissible Exposure to Ionizing Radiations" Symbol ENGRD-NT, dated November 25, 1960.

27. Connor, G. B., "Treatise on the Preliminary Hazards Summary Report for Nuclear Facilities," thesis for M. S. degree presented to the Air University, AD-215506, March 1959. 


\section{BIBLIOGRAPHY (CONT'D)}

28. Title 10 - Atomic Energy, Chapter I - Atomic Energy Commission, Part 50 - Licensing of Production and Utilization Facilities, Notice of Proposed Rule Making, April 8, 1961.

29. Ablitt, J. F., "Guide to Safety Report Requirements: 1. Stage 1 GasCooled Graphite Moderated Reactors," AHSB Report 41, May 1960.

30. Stewart, N. G., and Wilson, L., "The Organization at A.E.R.E., Harwell, for Safety Clearance of Reactors," AERE-R 2947, October 1959.

31. Brodsky, A and Beard, G. V., "A Compendium of Information for Use in Controlling Radiation Emergencies," TID-8206 (Rev.), September 1960.

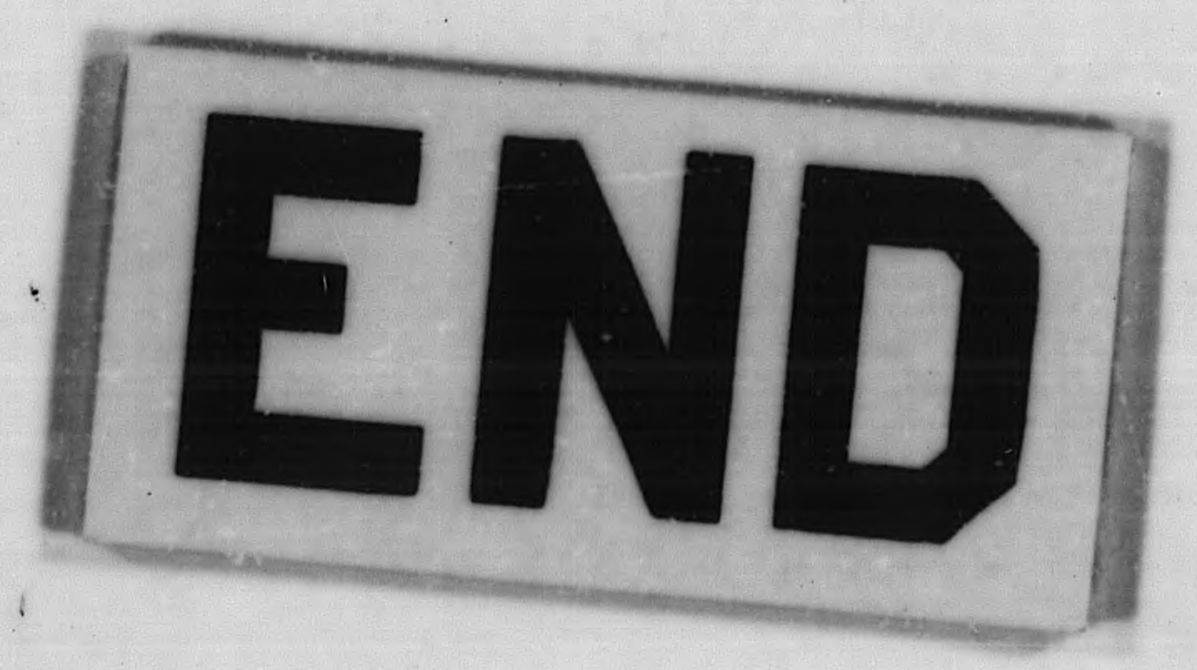

